\section{Diferenças de gênero ao acolhimento de pessoas vivendo com HIV em serviço universitário de referência de São Paulo, Brasil}

\author{
Gender differences among persons with HIV \\ admitted to a university reference \\ center in São Paulo, Brazil
}

\author{
${ }^{1}$ Faculdade de Saúde \\ Pública, Universidade de São \\ Paulo, São Paulo, Brasil. \\ 2 Faculdade de Medicina, \\ Universidade de São Paulo, \\ São Paulo, Brasil. \\ Correspondência \\ A. C. Segurado \\ Departamento de Moléstias \\ Infecciosas e Parasitárias, \\ Faculdade de Medicina, \\ Universidade de São Paulo. \\ Av. Dr. Enéas de Carvalho \\ Aguiar 470, São Paulo, SP \\ 05403-000, Brasil. \\ segurado@usp.br
} \section{The number of women living with HIV has in-
creased in Brazil, demanding special attention
to women's needs. To evaluate gender differences
at an HIV reference center in São Paulo, 1,072
patient medical records from 1998 and 2002
were reviewed. As compared to male counter-
parts, women tended to be younger and have less
schooling, and higher proportions of women were
married and heterosexual. Thirty-six percent of
women had undergone HIV testing because of creased in Brazil, demanding special attention
to women's needs. To evaluate gender differences
at an HIV reference center in São Paulo, 1,072
patient medical records from 1998 and 2002
were reviewed. As compared to male counter-
parts, women tended to be younger and have less
schooling, and higher proportions of women were
married and heterosexual. Thirty-six percent of
women had undergone HIV testing because of an HIV+ partner. In contrast, $43 \%$ of men had ssion, 55\% of men and 38\% of women} AIDS diagnosis. Women presented higher CD4+ cell counts and a higher proportion of undetectable HIV viral loads. No difference in access to antiretroviral therapy was seen after stratification for clinical status. Although the observed gender differences in socio-demographic characteristics emphasize women's social vulnerability to HIV, as compared to men, women in this cohort sought specialized care at earlier stages of infection. Knowledge about particular gender characteristics at admission to a reference center may contribute to organizing services delivery, improving care, and maximizing benefits.

HIV; Acquired Immunodeficiency Syndrome; Health Services Accessibility; Gender Identity 
as necessidades de pacientes de ambos os sexos. Para tanto, é essencial buscar diferenças que se justifiquem não apenas nas dimensões físicas e biológicas entre o organismo masculino e o feminino, mas também nas relações sociais que as organizam. O conceito de gênero é particularmente útil para essa análise, pois transcendendo as distinções biológicas, permite identificar diferenças que emergem da significação cultural do dimorfismo sexual da espécie humana 6,7. Ao lado disso, as distinções de gênero em aspectos epidemiológicos e clínicos dos pacientes mostram-se muito úteis em Saúde Pública, à medida em que permitem revelar desigualdades que apontam para perfis específicos de vulnerabilidade e identificar fatores relevantes para o desenho e implementação de ações de prevenção primária e secundária 8 .

\section{Pacientes e método}

\section{Seleção de pacientes}

Para avaliação neste estudo selecionaram-se homens e mulheres vivendo com HIV, atendidos no Serviço de Extensão ao Atendimento de Pacientes com HIV/AIDS (Casa da AIDS) da Divisão de Clínica de Moléstias Infecciosas e Parasitárias do Hospital das Clínicas da Faculdade de Medicina da Universidade de São Paulo (HC-FMUSP), entre janeiro de 1998 e dezembro de 2002, e acompanhados no serviço por período igual ou superior a trinta dias, intervalo habitual entre a consulta de admissão e o primeiro retorno ambulatorial para verificação de resultados de exames laboratoriais.

Após classificação por sexo e número de matrícula no serviço, sorteou-se, pelo método de amostragem sistemática ${ }^{9}$, uma amostra de 1.229 indivíduos dentre os 5.512 pacientes atendidos em consulta médica no período estabelecido.

\section{Procedimentos}

Procedeu-se a revisão dos prontuários médicos evolutivos dos pacientes, seguindo ficha padronizada de coleta de dados. As variáveis de interesse incluíram dados sócio-demográficos (sexo, idade ao diagnóstico sorológico de infecção por HIV, idade, escolaridade e estado civil à matrícula no serviço), dados relacionados à exposição ao HIV (principal categoria de exposição, motivo para realização do teste anti-HIV), além de dados clínicos e laboratoriais à admissão no serviço (estádio clínico da infecção pelo HIV, determinação quantitativa de linfócitos CD4+ periféricos e carga viral plasmática de HIV, tratamento anti- retroviral recebido antes do ingresso no serviço e marcadores sorológicos de infecção por outros agentes de transmissão sangüínea e/ou sexual - hepatite B, hepatite C, HTLV, sífilis). Considerou-se como terapia anti-retroviral de alta potência (HAART) o tratamento com pelo menos um medicamento inibidor da protease viral (IP) ou inibidor não nucleosídico da transcriptase reversa (ITRNN), em combinação com no mínimo dois medicamentos inibidores nucleosídicos da transcriptase reversa (ITRN). As fichas padronizadas foram transcritas para um banco de dados informatizado utilizando o programa EpiData, versão 2.1 (EpiData Assoc., Odense, Dinamarca; http://www.epidata.dk/index.htm).

As variáveis qualitativas de interesse foram apresentadas em tabelas de freqüência e para as variáveis quantitativas estimaram-se medidas de tendência central e de dispersão. Para as que não apresentavam distribuição normal, utilizou-se a mediana, acompanhada de valores mínimo e máximo. Empregou-se a estatística qui-quadrado para comparar proporções, e o teste $t$ de Student ou de Mann-Whitney para comparação de médias e medianas, respectivamente. As análises estatísticas foram conduzidas utilizando-se o programa Stata, versão 8.0 (Stata Corp., College Station, Estados Unidos) e adotando-se nível de significância de $5 \%$.

\section{Aspectos éticos}

O protocolo da pesquisa foi aprovado pela Comissão de Ética para Análise de Projetos de Pesquisa do HC-FMUSP e pelo Comitê de Ética da Faculdade de Saúde Pública da Universidade de São Paulo. Por se tratar de estudo baseado em revisão de prontuários, prescindiu-se de termo de consentimento livre e esclarecido, mas garantiu-se o anonimato dos sujeitos e o sigilo no manuseio das informações.

\section{Resultados}

Da amostra sorteada, composta de 1.229 pacientes atendidos na Casa da AIDS no período estabelecido, 157 (12,8\%) foram excluídos da análise em razão de terem prontuários extraviados ( $\mathrm{n}=16$ ), acompanhamento no serviço por um período inferior a trinta dias $(n=113)$ ou resultado negativo ao teste sorológico para infecção por HIV $(n=28)$. A população analisada neste estudo foi, portanto, composta por 1.072 pacientes com HIV/AIDS.

A maioria dos indivíduos analisados (71\%) era do sexo masculino. As mulheres foram diagnosticadas em idades mais jovens, quando compara- 
das aos homens $(\mathrm{p}=0,03)$ (Tabela 1$)$. Os homens eram em sua maioria solteiros e apresentavam escolaridade igual ou superior a 11 anos. Em contraste, na população feminina, $48 \%$ das mulheres eram casadas ou amasiadas, $67 \%$ tinham menos de 11 anos de escolaridade e $23 \%$ eram donasde-casa. No que se refere à categoria de exposição ao HIV, 77\% ( $n=567)$ dos homens relataram comportamento homossexual ou bissexual.

A análise do momento do diagnóstico permitiu identificar que o motivo para a realização do teste sorológico anti-HIV diferiu entre os sexos $(p<0,001)$. Enquanto $36 \%$ das mulheres o fizeram por possuírem parceiro soropositivo, na população masculina o motivo principal da testagem sorológica (43\%) foi a ocorrência de sintomas sugestivos de infecção por HIV/AIDS. Observou-se também que 110 (16\%) homens recorreram ao teste por se perceberem sob risco e que $35(12 \%)$ mulheres foram diagnosticadas por meio da triagem laboratorial oferecida durante o pré-natal.

A matrícula na Casa da AIDS foi efetuada por $47 \%$ dos pacientes em até dois meses após o diagnóstico de infecção por HIV, não se verificando diferença estatisticamente significativa entre os sexos no intervalo entre a data do diagnóstico e a admissão no serviço $(p=0,49)$. Quando da admissão à Casa da AIDS, os homens apresentavam-se mais freqüentemente em fase mais avançada da história natural da infecção. O estádio clínico de AIDS foi reconhecido em 418 (55\%) homens e em 117 (38\%) mulheres $(\mathrm{p}<0,001)$. Dentre todos os pacientes com AIDS à matrícula no serviço ( $n=535)$, a maioria ( $52 \%$ ) já havia apresentado pelo menos uma afecção oportunista antes da primeira consulta na Casa da AIDS, sendo as mais freqüentemente diagnosticadas: candidíase esofágica, pneumonia por Pneumocystis carinii e tuberculose pulmonar.

No que se refere à avaliação de marcadores laboratoriais evolutivos da infecção por HIV/AIDS, pode-se observar que as mulheres foram admitidas ao serviço com um número mais elevado de linfócitos CD4+em sangue periférico (mediana = 297 células $/ \mathrm{mm}^{3}$, mínimo $=0$, máximo $=3.692$ ) do que os homens (mediana $=233$ células $/ \mathrm{mm}^{3}$, mínimo $=0$, máximo $=1.320)(\mathrm{p}=0,002$, teste de Mann-Whitney). Considerando a importância da determinação do número de linfócitos CD4+ em sangue periférico na avaliação do estado imunológico do paciente, avaliou-se a distribuição de homens e mulheres atendidos no serviço segundo diferentes intervalos de contagem dessas células (Tabela 2).

No momento da admissão ao serviço, verificou-se também que as mulheres apresentavam maior proporção de carga viral plasmática de HIV indetectável, quando comparadas aos homens $58(19 \%)$ e $101(14 \%)$, respectivamente $(\mathrm{p}=0,02$; dados ignorados para 9 mulheres e 18 homens). Dentre os 159 pacientes com carga viral indetectável na avaliação inicial no serviço, 42 (26\%) encontravam-se sob tratamento anti-retroviral (31 com HAART), não havendo diferença entre os se$x o s(p=0,22)$. Assim, nota-se que independentemente do uso de medicamentos anti-retrovirais, as mulheres apresentavam com maior freqüência ausência de viremia plasmática. Da mesma forma, dentre aqueles com carga viral detectável ( $\mathrm{n}=886)$, observou-se que as mulheres $(\log \mathrm{da}$ carga viral plasmática: mediana $=4,3$ cópias $/ \mathrm{mL}$, mínimo $=2,0$, máximo $=6,6$ ) apresentaram viremia plasmática menor que os homens (mediana $=4,5$ cópias $/ \mathrm{mL}$, mínimo $=1,9$, máximo $=6,7$ ) ( $\mathrm{p}=0,02$, teste de Mann-Whitney)

Procurou-se avaliar a presença de marcadores séricos de outras infecções de transmissão sexual ou sangüínea por ocasião da admissão dos pacientes na Casa da AIDS (Tabela 3). Dos 20 casos com triagem sorológica positiva para infecção por HTLV pelo método de ensaio imunoenzimático (ELISA), 14 foram submetidos à avaliação pelo método de Western Blot, com confirmação desta infecção retroviral em 11 (79\%) pacientes, sendo 6 do sexo feminino. Houve maior prevalência de marcadores sorológicos de infecção pregressa e de infecção atual pelo vírus da hepatite B e de soropositividade para sífilis entre os homens.

Quanto à abordagem terapêutica, 204 (19\%) pacientes encontravam-se em tratamento antiretroviral à admissão ao serviço, com diferença significativa $(p=0,001)$ entre homens e mulheres (22\% e 13\%, respectivamente) (Figura 1). Estratificando-se os pacientes segundo estádio clínico à matrícula, notou-se não haver diferença entre os sexos para o tipo de tratamento anti-retroviral recebido (Tabela 4). Dos casos admitidos ao serviço com AIDS e sem história de tratamento anti-retroviral $(n=386)$, a metade havia recebido o diagnóstico de infecção por HIV há menos de quarenta dias.

\section{Discussão}

Neste estudo, identificaram-se diferenças significativas entre homens e mulheres no momento de seu acolhimento em serviço universitário de referência no cuidado de pessoas vivendo com HIV. As distinções de gênero observadas incluem características sócio-demográficas, fatores associados ao modo de exposição à infecção, o estádio clínico em que se encontravam e os marcadores laboratoriais de importância prognóstica 
Distribuição dos pacientes com HIV/AIDS atendidos na Casa da AIDS segundo características à matrícula no serviço. São Paulo, Brasil, 1998 a 2002.

\begin{tabular}{|c|c|c|c|c|c|}
\hline \multirow[t]{2}{*}{ Características } & \multicolumn{2}{|c|}{ Feminino $(n=310)$} & \multicolumn{2}{|c|}{ Masculino $(n=762)$} & \multirow[t]{2}{*}{ p } \\
\hline & $\mathbf{n}$ & $\%$ & $\mathbf{n}$ & $\%$ & \\
\hline Idade ao diagnóstico de infecção por HIV (anos) * & & & & & 0,03 \\
\hline$<20$ & 18 & 5,8 & 22 & 2,9 & \\
\hline $20-29$ & 118 & 38,3 & 250 & 33,2 & \\
\hline $30-39$ & 111 & 36,0 & 333 & 44,2 & \\
\hline $40-49$ & 44 & 14,3 & 113 & 15,0 & \\
\hline$\geq 50$ & 17 & 5,5 & 35 & 4,7 & \\
\hline Estado civil ** & & & & & $<0,001$ \\
\hline Solteiro(a) & 72 & 23,8 & 490 & 66,0 & \\
\hline Casado(a)/Amasiado(a) & 146 & 48,2 & 192 & 25,9 & \\
\hline Viúvo(a) & 41 & 13,5 & 14 & 1,9 & \\
\hline Divorciado(a)/Desquitado(a) & 44 & 14,5 & 46 & 6,2 & \\
\hline Escolaridade $* \star \star$ & & & & & $<0,001$ \\
\hline Analfabeto/Primário incompleto & 29 & 9,7 & 22 & 3,0 & \\
\hline Primário completo/Ginásio incompleto & 79 & 26,4 & 129 & 17,8 & \\
\hline Ginásio completo/Colegial incompleto & 91 & 30,4 & 185 & 25,6 & \\
\hline Colegial completo/Superior incompleto & 66 & 22,1 & 253 & 35,0 & \\
\hline Superior completo & 34 & 11,4 & 134 & 18,5 & \\
\hline Ano do diagnóstico de infecção por HIV * & & & & & 0,14 \\
\hline Antes de 1990 & 8 & 2,6 & 34 & 4,5 & \\
\hline Entre 1990 e 1996 & 123 & 39,9 & 328 & 43,6 & \\
\hline Entre 1997 e 2002 & 177 & 57,5 & 391 & 51,9 & \\
\hline Categoria de exposição ao HIV \# & & & & & $<0,001$ \\
\hline Sangüínea & 10 & 3,6 & 77 & 12,0 & \\
\hline Sexual & 267 & 96,4 & 567 & 88,0 & \\
\hline Motivo para realização do teste anti-HIV \#\# & & & & & $<0,001$ \\
\hline Sintomas sugestivos de infecção por HIV/AIDS & 81 & 27,5 & 299 & 42,8 & \\
\hline Triagem sorológica em banco de sangue & 19 & 6,4 & 57 & 8,2 & \\
\hline Assintomático com parceiro(a) soropositivo(a) & 107 & 36,3 & 104 & 14,9 & \\
\hline Percepção de risco & 14 & 4,8 & 110 & 15,8 & \\
\hline Outros & 74 & 25,1 & 128 & 18,3 & \\
\hline Estádio clínico à matrícula \#\#\# & & & & & $<0,001$ \\
\hline Sem AIDS & 193 & 62,3 & 341 & 44,9 & \\
\hline Com AIDS & 117 & 37,7 & 418 & 55,1 & \\
\hline
\end{tabular}

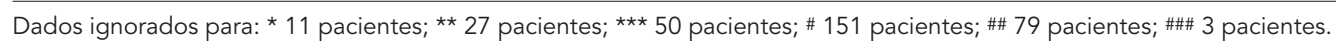

que exibiam ao iniciar o acompanhamento especializado.

Analogamente ao descrito em outros países $10,11,12,13,14,15,16$, as mulheres avaliadas em São Paulo mostraram-se mais jovens que os homens ao diagnóstico de infecção por HIV. Sabe-se que a mucosa genital das meninas mais jovens é mais delgada e, portanto, mais vulnerável à aquisição do HIV 2. Além disso, sabe-se que a chance de uma jovem se infectar é maior que a de um rapaz da mesma idade. Na África do Sul, Zâmbia e Zimbábue, entre jovens de 15 a 24 anos, as mulheres apresentam risco de infecção entre 3 e 6 vezes maior que os homens 17 .

Adicionalmente à vulnerabilidade biológica própria do sexo feminino, questões sócio-comportamentais relacionadas a desigualdades de gênero podem justificar essa diferença. As mulheres jovens geralmente se relacionam sexualmente com homens mais velhos que, por sua vez, apresentam maior probabilidade de ter contraído alguma doença sexualmente transmissível (DST) em suas relações anteriores 18 . Reconhece-se que um indivíduo com DST apresenta um risco dez 
Distribuição dos pacientes com HIV/AIDS segundo sexo e resultado da determinação quantitativa de linfócitos CD4+ no sangue periférico/mm³ à matrícula na Casa da AIDS. São Paulo, Brasil, 1998 a 2002.

\begin{tabular}{|c|c|c|c|c|c|}
\hline & \multicolumn{2}{|c|}{ Feminino $(n=308)$} & \multicolumn{2}{|c|}{ Masculino $(n=758)$} & \multirow[t]{2}{*}{$p$} \\
\hline & $\mathrm{n}$ & $\%$ & $\mathrm{n}$ & $\%$ & \\
\hline CD4+ inicial (número de células/mm³) & & & & & 0,008 \\
\hline$<100$ & 59 & 19,2 & 202 & 26,6 & \\
\hline $100-199$ & 42 & 13,6 & 142 & 18,7 & \\
\hline $200-299$ & 54 & 17,5 & 109 & 14,4 & \\
\hline $300-399$ & 48 & 15,6 & 102 & 13,5 & \\
\hline $400-499$ & 39 & 12,7 & 87 & 11,5 & \\
\hline$\geq 500$ & 66 & 21,4 & 116 & 15,3 & \\
\hline
\end{tabular}

Tabela 3

Número e porcentagem de pacientes HIV/AIDS com marcadores sorológicos de infecções de transmissão sangüínea e/ou sexual, atendidos na Casa da AIDS segundo sexo. São Paulo, Brasil, 1998 a 2003

\begin{tabular}{|c|c|c|c|c|c|c|c|}
\hline & \multicolumn{3}{|c|}{ Feminino $(n=308)$} & \multicolumn{3}{|c|}{ Masculino $(n=758)$} & \multirow[t]{3}{*}{$\mathrm{p}$} \\
\hline & \multirow[t]{2}{*}{$\mathrm{n}$} & \multicolumn{2}{|c|}{ Reagente } & \multirow[t]{2}{*}{$\mathrm{n}$} & \multicolumn{2}{|c|}{ Reagente } & \\
\hline & & $\mathrm{n}$ & $\%$ & & $\mathrm{n}$ & $\%$ & \\
\hline HTLV ELISA & 105 & 10 & 9,5 & 199 & 10 & 5,0 & 0,13 \\
\hline Hepatite B (anti-HBc) & 275 & 50 & 18,2 & 654 & 344 & 52,6 & $<0,001$ \\
\hline Hepatite B (Ag-HBs) & 271 & 8 & 3,0 & 641 & 57 & 8,9 & 0,001 \\
\hline Hepatite C (anti-HCV) & 289 & 34 & 11,8 & 690 & 114 & 16,5 & 0,06 \\
\hline Antitreponema & 252 & 24 & 9,5 & 583 & 193 & 33,1 & 0,001 \\
\hline Chagas & 179 & 4 & 2,2 & 387 & 9 & 2,3 & 0,95 \\
\hline
\end{tabular}

Figura 1

Distribuição de pacientes HIV/AIDS atendidos na Casa da AIDS segundo sexo e tipo de tratamento anti-retroviral recebido antes da matrícula no serviço. São Paulo, Brasil, 1998 a 2002.
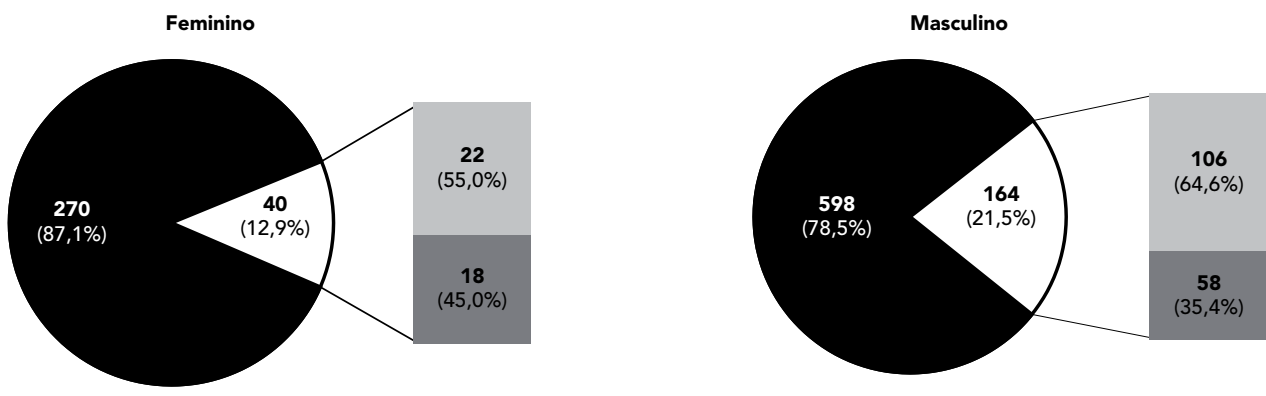

Sem tratamento anti-retroviral 
Distribuição dos pacientes com HIV/AIDS segundo sexo, estádio clínico e tratamento anti-retroviral recebido à matrícula na Casa da AIDS. São Paulo, Brasil, 1998 a 2003.

\begin{tabular}{|c|c|c|c|c|c|}
\hline \multirow{2}{*}{$\begin{array}{l}\text { Estádio clínico e } \\
\text { tratamento recebido }\end{array}$} & \multicolumn{2}{|c|}{ Feminino $(n=308)$} & \multicolumn{2}{|c|}{ Masculino $(n=758)$} & \multirow[t]{2}{*}{$p$} \\
\hline & $n$ & $\%$ & $\mathbf{n}$ & $\%$ & \\
\hline Sem AIDS $(n=534)$ & & & & & 0,22 \\
\hline Sem TARV & 179 & 92,8 & 301 & 88,3 & \\
\hline Com TARV/Sem HAART & 7 & 3,6 & 24 & 7,0 & \\
\hline Com TARV/Com HAART & 7 & 3,6 & 16 & 4,7 & \\
\hline Com AIDS $(n=535)$ & & & & & 0,12 \\
\hline Sem TARV & 91 & 77,8 & 295 & 70,6 & \\
\hline Com TARV/Sem HAART & 11 & 9,4 & 34 & 8,1 & \\
\hline Com TARV/Com HAART & 15 & 12,8 & 89 & 21,3 & \\
\hline
\end{tabular}

TARV: tratamento anti-retroviral; HAART: terapia anti-retroviral de alta potência.

vezes aumentado de adquirir ou de transmitir o HIV 19.

Ao lado disso, em parcerias sexuais entre mulheres jovens e homens mais velhos, freqüentemente se verifica disparidade econômica, que resulta em menor poder de negociação por parte da mulher pelo uso do preservativo 18 . No Brasil, segundo Parker \& Galvão 4, esse domínio dos homens em relação à utilização ou não da camisinha procede das desigualdades nas relações de poder e de gênero.

Em relação à população estudada, observouse ainda que os homens, em geral, eram solteiros, homossexuais ou bissexuais e apresentavam oito ou mais anos de escolaridade, ao passo que as mulheres eram mais freqüentemente casadas ou amasiadas, donas-de-casa, apresentavam a heterossexualidade como principal forma de exposição ao vírus e tinham baixa escolaridade.

No que tange à distribuição das categorias de exposição ao HIV entre os sexos, resultados semelhantes foram descritos em estudos realizados no Rio de Janeiro 20, no Canadá 12, nos Estados Unidos 14,16 e em Londres, no Reino Unido 21. Contudo, no Brasil, esse perfil foi predominante no período compreendido entre 1980 e 1992; desde então a população masculina passou a apresentar aumento na incidência de casos entre os heterossexuais, que hoje totalizam a maioria dos casos de AIDS do país 22 .

Essa divergência em relação ao observado no conjunto da casuística brasileira de AIDS não parece devida ao tempo de diagnóstico dos pacientes analisados neste estudo, dado que apenas $12 \%$ dos homens foram identificados com a doença até 1992. Sugere-se, assim, haver uma característica particular da clientela do serviço com maior representação porcentual da categoria homossexual/bissexual entre os homens ali assistidos.

O predomínio de mulheres casadas e de menor escolaridade na amostra avaliada aparentemente reflete o contexto atual da epidemia brasileira de HIV/AIDS, denotando a particular vulnerabilidade social exibida pela população feminina. O conceito de vulnerabilidade social, proposto por Mann et al. 23 e revisitado por Ayres et al. ${ }^{24}$, enfatiza que o adoecimento resulta de aspectos individuais e coletivos, além dos fatores individuais. Refere-se especificamente aos modos de inserção dos indivíduos na sociedade, que favorecem sua susceptibilidade ao agravo à saúde em questão, incluindo relações de gênero; iniqüidades raciais, religiosas, culturais; e de acesso à educação, aos meios de comunicação, às possibilidades de geração de renda e de consumo.

Seu impacto no tocante à infecção pelo HIV e à AIDS é significativo. Em entrevistas realizadas por Nascimento et al. 25 em Camaragibe, Região Metropolitana de Recife, com mulheres casadas, dependentes dos maridos e com rendas de até dois salários mínimos, por exemplo, observaramse evidências da maior vulnerabilidade feminina frente à infecção pelo HIV. Essas mulheres identificaram o casamento como barreira contra a doença e chegaram até mesmo a desconhecer sua etiologia e os modos de contágio. Não se percebiam sob risco de adquirir a infecção e viam a AIDS como doença dos outros.

A evolução temporal da epidemia de AIDS no Brasil segundo sexo, ocupação, status sócioeconômico e categoria de exposição, descrita por Fonseca et al. 26, aponta também para a pauperização. Os maiores aumentos nos coeficientes 
de incidência da doença deram-se entre aqueles com menor status sócio-econômico para ambos os sexos. Os homens "desempregados" apresentaram crescimento anual percentual de $23 \%$ entre 1991 e 1996. Os pesquisadores também encontraram predominância feminina entre aqueles indivíduos sem participação no mercado de trabalho; a categoria "afazeres domésticos" apresentou os maiores coeficientes de incidência da doença e o maior crescimento porcentual anual (22\%). Em contraste, para as pessoas classificadas entre as $20 \%$ mais ricas da população brasileira, houve expressiva redução nas taxas de incidência da doença.

Um aspecto relevante deste estudo diz respeito às diferenças observadas entre os sexos nos motivos que levam as pessoas a buscar o teste diagnóstico de infecção por HIV. Enquanto os homens mais freqüentemente realizaram o teste sorológico anti-HIV por apresentarem algum indício clínico da infecção, ou por se perceberem sob risco, as mulheres o fizeram após conhecimento da soropositividade do parceiro ou durante rastreamento na assistência pré-natal. A baixa busca espontânea pelo diagnóstico na população feminina provavelmente reflete, mais uma vez, a falta de percepção de risco entre elas, o que pode acarretar retardo no reconhecimento da infecção e conseqüentemente no acesso às intervenções profiláticas e terapêuticas, aumentando a vulnerabilidade ao adoecimento na população feminina.

Apesar disso, na coorte estudada em São Paulo, não se observou diferença entre homens e mulheres no tempo decorrido entre o diagnóstico de soropositividade e a admissão ao serviço especializado no cuidado a pessoas que vivem com HIV, à semelhança de relatos prévios relativos a pacientes austríacos 8 ou norte-americanos acompanhados nas regiões metropolitanas de Chicago e Cleveland 14,16. Tal fato parece apontar em nossa série de casos para a inexistência de desigualdade de gênero no acesso ao cuidado especializado, talvez em função da universalidade do acesso ao cuidado e ao tratamento gratuito providos pelo sistema público de saúde em nosso país. Essa situação contrasta com dados da Organização Mundial da Saúde que indicam haver iniqüidades de gênero no acesso ao cuidado e ao tratamento em várias regiões do mundo. Tais diferenças muitas vezes extrapolam as restrições econômicas, e em diversos contextos sócio-culturais associam-se fortemente ao estigma e discriminação vividos particularmente pela população feminina após a revelação do diagnóstico de infecção pelo HIV 27.

Outra constatação relevante para o planejamento das ações de saúde diz respeito às de- mandas previstas para o cuidado desses pacientes. Em nosso estudo as mulheres chegaram ao serviço especializado em estádio clínico menos avançado da infecção por HIV, quando comparadas aos homens. Tal fato era, contudo, esperado, visto que, como descrito acima, foram levadas ao teste ainda assintomáticas, mais freqüentemente após solicitação médica por possuírem parceiros soropositivos ou na triagem sorológica conduzida durante o pré-natal.

O estádio clínico menos avançado aparece também refletido nos marcadores laboratoriais avaliados à matrícula no serviço. As mulheres foram admitidas na Casa da AIDS com maior número de linfócitos CD4+ em sangue periférico e, em maior proporção, com carga viral plasmática de HIV indetectável, quando comparadas aos homens. Analogamente, em estudos realizados em países desenvolvidos, encontraram-se melhores resultados nos marcadores laboratoriais evolutivos para a população feminina à avaliação inicial 12,13,15,16,28.

Deve-se, entretanto, atentar que determinações menos elevadas da carga viral plasmática foram já relatadas em outros estudos entre mulheres vivendo com HIV quando comparadas aos homens, mesmo após ajuste para outros marcadores prognósticos, como número de células CD4+ periféricas, idade e presença de sintomas clínicos 29,30,31,32,33. Tais achados sugerem que independentemente do estádio evolutivo do paciente ao longo da história natural da infecção, a dinâmica de replicação viral possa ser menos produtiva nas mulheres, se comparadas aos homens. Tal diferença pode relacionar-se a distintos estados de ativação celular ou a fatores hormonais capazes de modular a replicação do HIV 34.

Outro aspecto a ser destacado na análise comparativa entre os sexos diz respeito ao acesso dos pacientes à terapia anti-retroviral, tendo em vista o forte impacto que esta intervenção determina sobre o prognóstico da infecção. Embora as pacientes do sexo feminino deste estudo tenham obtido o diagnóstico da infecção pelo HIV mais recentemente que os homens, a avaliação do acesso ao tratamento anti-retroviral à admissão ao serviço não identificou diferença entre os sexos quanto ao uso de HAART após estratificação da amostra segundo o estádio clínico da doença.

No Brasil, a política de distribuição de antiretrovirais garante o acesso universal e gratuito aos medicamentos a todos os pacientes que preenchem os critérios estabelecidos pelo Ministério da Saúde 35. Essa iniciativa parece justificar a inexistência de diferença no acesso ao tratamento na população estudada.

Em outros países, ao contrário, a situação parece distinta. Hader et al. 36 acreditam que, tal- 
vez por motivos sócio-econômicos, as mulheres norte-americanas apresentem menor chance de usar anti-retrovirais. Um recente estudo multicêntrico realizado nos Estados Unidos mostrou, após análise multivariada, ser o sexo feminino independentemente associado ao menor uso de medicamentos anti-retrovirais 37 . O mesmo foi observado por Strathdee et al. 38 entre pacientes usuários de droga injetável (UDI) no Canadá, não obstante o acesso gratuito à terapia medicamentosa naquele país. Para se garantir o acesso eqüitativo ao cuidado para mulheres jovens e adultas, o Joint United Nations Programme on HIV/AIDS (UNAIDS) 39 reconhece ser preciso implementar mudanças de atitude em vários países, de modo a remover barreiras estruturais ao tratamento que incluem, entre outros, regulamentos e legislações discriminatórias.

Muitos programas de prevenção primária e secundária relacionados à infecção pelo HIV não levam em conta as desigualdades entre os sexos. $\mathrm{Na}$ realidade, as mulheres enfrentam maior vulnerabilidade à infecção e ao adoecimento, na dependência de fatores que não afetam igualmente os homens, muitos dos quais estão implícitos nas relações sociais e nas realidades econômicas das sociedades 17. Assim, por exemplo, ao investigar o grau de conhecimento e as percepções de pessoas vivendo com HIV em diversas localidades da região sudeste dos Estados Unidos acerca dos recursos disponíveis para o cuidado clínico especializado e a rede comunitária de benefícios de suporte social, Whetten et al. ${ }^{40}$ verificaram que as mulheres mais freqüentemente desconheciam como acessá-los ou os julgavam menos

\section{Resumo}

O número de mulheres brasileiras vivendo com HIV aumentou, exigindo dos serviços especializados atenção às demandas femininas. Neste estudo avaliaramse diferenças de gênero ao acolhimento em serviço de referência no cuidado a pessoas vivendo com HIV em São Paulo, com revisão de 1.072 prontuários de pacientes atendidos entre 1998 e 2002. As mulheres eram mais jovens, mais freqüentemente casadas e heterossexuais e apresentavam menor escolaridade do que os homens à admissão. Enquanto 36\% das mulheres realizaram teste anti-HIV por possuírem parceiro soropositivo, 43\% dos homens o fizeram por apresentarem sintomas. Ao acolhimento, 55\% dos homens e 38\% das mulheres tinham AIDS. As mulheres apresentaram contagem de linfócitos CD4+ mais elevada e, mais úteis. Tais barreiras, se não superadas, podem acarretar prejuízo para o cuidado de mulheres que vivem com HIV, com potencial repercussão sobre sua sobrevida e/ou qualidade de vida.

De um modo geral, o cuidado às pessoas com HIV/AIDS baseia-se em estratégias dirigidas ao conjunto da população acometida pela infecção. Entretanto, o benefício de tais intervenções pode variar significativamente entre homens e mulheres, em função das distinções de gênero aqui descritas em aspectos epidemiológicos e clínicos dos pacientes no momento de seu acolhimento em uma unidade especializada no cuidado.

A identificação de tais fatores e conseqüentemente de diferenças na vulnerabilidade ao cuidado pode contribuir para adequar a estruturação dos serviços, de modo a capacitá-los a responder adequadamente a demandas específicas de homens e mulheres que vivem com HIV em tempos de HAART, visando a aprimorar a qualidade da assistência prestada e otimizar os benefícios das intervenções em sua saúde.

É importante, ainda, reconhecer que os resultados obtidos em nosso estudo devem ser analisados à luz de suas limitações. Foram avaliados apenas pacientes de um centro universitário de referência no cuidado a pessoas vivendo com HIV, o que não reflete a diversidade de cenários nos quais a assistência a estes pacientes é prestada, dificultando assim generalizações. Não obstante, cremos que a condução de estudos a partir das vivências rotineiras em serviços de saúde permite o melhor conhecimento da realidade prática na assistência à saúde e pode mostrar-se útil para o aprimoramento das ações ali conduzidas. freqüentemente, carga viral indetectável. Não houve diferença entre os sexos no acesso ao tratamento antiretroviral após estratificação por estádio clínico. Embora as diferenças sócio-demográficas observadas à admissão apontem para a vulnerabilidade social das mulheres, estas buscaram cuidado especializado em estágios clínicos menos avançados. O conhecimento de características distintivas entre homens e mulheres ao acolhimento pode contribuir para estruturar serviços, aprimorar a assistência e otimizar os benefícios do cuidado.

HIV; Síndrome de Imunodeficiência Adquirida; Acesso aos Serviços de Saúde; Gênero 


\section{Colaboradores}

P. E. Braga participou da concepção do protocolo de pesquisa e da elaboração do instrumento de coleta de dados, incumbiu-se do tratamento e análise dos dados e da redação do manuscrito. M. R. A. Cardoso colaborou na elaboração do instrumento de coleta de dados, supervisionou o tratamento e análise dos dados e contribuiu para a redação do manuscrito. A. C. Segurado contribuiu na concepção do protocolo de pesquisa e do instrumento de coleta de dados, responsabilizou-se pela coleta de dados em campo e contribuiu na interpretação dos resultados e na redação do manuscrito.

\section{Agradecimentos}

Este trabalho contou com o apoio financeiro do Conselho Nacional de Desenvolvimento Científico e Tecnológico (CNPq), por meio de bolsa de doutorado concedida a P. E. B. (processo no ${ }^{\circ}$ 140840/2003-6).

\section{Referências}

1. Joint United Nations Programme on HIV/AIDS. AIDS epidemic update. Geneva: Joint United Nations Programme on HIV/AIDS; 2005.

2. Pan American Health Organization. Women and HIV/AIDS: prevention and care strategies. Washington DC: Pan American Health Organization; 2000.

3. Joint United Nations Programme on HIV/AIDS. Report on the global AIDS epidemic. Geneva: Joint United Nations Programme on HIV/AIDS; 2004.

4. Parker R, Galvão J. Quebrando o silêncio: mulheres e AIDS no Brasil. Rio de Janeiro: Editora RelumeDumará/Associação Brasileira Interdisciplinar de AIDS/Instituto de Medicina Social, Universidade do Estado do Rio de Janeiro; 1996.

5. Ministério da Saúde. Boletim Epidemiológico AIDS 2004; 17(1).

6. Heilborn ML. De que gênero estamos falando? Sexualidade, Gênero e Sociedade 1994; (2):1-8.

7. Scott J. Gênero: uma categoria útil de análise histórica. Educação e Realidade 1995; 20:71-99.

8. Rohlfs I, Borrel C, Fonseca MC. Género, desigualdades y salud pública: conocimientos y desconocimientos. Gac Sanit 2000; 14 Suppl 3:60-71.
9. Kalton G. Introduction to survey sampling. Beverly Hills: Sage Publications; 1983.

10. Dunne MT, Ruskin HJ, Mulcahy FM. Survival with AIDS in Ireland. AIDS 1997; 11:1281-90.

11. Armbruster C, Kriwanek S, Vorbach H. Genderspecific differences in the natural history, clinical features, and socioeconomic status of HIV-infected patients: experience of a treatment centre in Vienna. Wien Klin Wochenschr 2000; 17:754-60.

12. Mocroft A, Gill MJ, Davidson W, Phillips AN. Are there gender differences in starting protease inhibitors, HAART, and disease progression despite equal access to care? J Acquir Immune Defic Syndr $2000 ; 24: 475-82$.

13. Moore AL, Kirk O, Johnson AM, Katlama C, Blaxhult A, Dietrich M, et al. Virologic, immunologic, and clinical response to highly active antiretroviral therapy: the gender issue revisited. J Acquir Immune Defic Syndr 2003; 32:452-61.

14. Kenagy G, Linsk NL, Bruce D, Warnecke R, Gordon A, Wagaw F, et al. Service utilization, service barriers and gender among HIV-positive consumers in primary care. AIDS Patient Care STDS 2003; 17:235-44. 
15. Nicastri E, Angeletti C, Palmisano L, Sarmati L, Chiesi A, Geraci A, et al. Gender differences in clinical progression of HIV-1-infected individuals during long-term highly active antiretroviral therapy. AIDS 2005; 19:577-83.

16. Loupa CV, Rodriguez B, McComsey G, Gripshover B, Salata RA, Valdez H, et al. Gender differences in human immunodeficiency virus (HIV) RNA and CD4 cell counts among new entrants to HIV care. Clin Microbiol Infect 2006; 12:389-91.

17. Joint United Nations Programme on HIV/AIDS. Situación de la epidemia de SIDA: 2004. Geneva: Organización Mundial de la Salud; 2004.

18. Türmen T. Gender and HIV/AIDS. Int J Gynaecol Obstet 2003; 82:411-8.

19. Joint United Nations Programme on HIV/AIDS. Gender and HIV/AIDS. Geneva: Joint United Nations Programme on HIV/AIDS; 2003.

20. Santoro-Lopes G, Harrison LH, Moulton LH, Lima LAA, Pinho AMF, Hofer C, et al. Gender and survival after AIDS in Rio de Janeiro, Brazil. J Acquir Immune Defic Syndr Hum Retrovirol 1998; 19: 403-7.

21. Moore AL, Sabin CA, Johnson MA, Phillips NA. Gender and clinical outcomes after starting highly active antiretroviral treatment: a cohort study. J Acquir Immune Defic Syndr 2002; 29:197-202.

22. Chequer P. Apresentação. Boletim Epidemiológico AIDS DST 2005; 1:3-5.

23. Mann J, Tarantola D, Netter T, editors. AIDS in the world. Cambridge/London: Harvard University Press; 1992

24. Ayres JRCM, Calazans GJ, Saletti Filho H, França Jr. I. O conceito de vulnerabilidade e prevenção e as práticas de saúde. In: Czeresnia D, Freitas CM, organizadores. Promoção em saúde: conceitos, reflexões e tendências. Rio de Janeiro: Editora Fiocruz; 2003. p. 117-40.

25. Nascimento AMG, Barbosa CS, Medrado B. Mulheres em Camaragibe: representação social sobre a vulnerabilidade feminina em tempos de AIDS. Rev Bras Saúde Matern Infant 2005; 5:77-86.

26. Fonseca MG, Travassos C, Bastos FI, Silva NV, Szwarcwald CL. Distribuição social da AIDS no Brasil, segundo participação no mercado de trabalho, ocupação e status sócio-econômico dos casos de 1987 a 1998. Cad Saúde Pública 2003; 19: 1351-63.

27. Joint United Nations Programme on HIV/AIDS. Ensuring equitable access to antiretroviral treatment for women. Geneva: Joint United Nations Programme on HIV/AIDS; 2004.

28. Box TL, Olsen M, Oddone EZ, Ketz SA. Healthcare access and utilization by patients infected with human immunodeficiency virus: does gender matter? J Womens Health (Larchmt) 2003; 12:391-7.
29. Evans JS, Nims T, Cooley J, Bradley W, Jagodzinski L, Zhou S, et al. Serum levels of virus burden in early-stage human immunodeficiency virus type 1 disease in women. J Infect Dis 1997; 175:795-800.

30. Farzadegan H, Hoover DR, Astemborski J, Lyles CM, Margolick JB, Markham RB, et al. Sex differences in HIV-1 viral load and progression to AIDS. Lancet 1998; 352:1510-4.

31. Anastos K, Gange SJ, Lau B, Weiser B, Detels R, Giorgi JV, et al. Association of race and gender with HIV-1 RNA levels and immunologic progression. J Acquir Immune Defic Syndr 2000; 24:218-26.

32. Currier JS, Spino C, Grimes J, Wofsy CS, Katzenstein DA, Hughes MD, et al. Differences between women and men in adverse events and CD4+ responses in nucleoside analogue therapy for HIV infection. J Acquir Immune Defic Syndr 2000; 24:316-24.

33. Napravnik S, Poole C, Thomas JC, Eron Jr. JE. Gender difference in HIV RNA levels: a meta-analysis of published studies. J Acquir Immune Defic Syndr 2002; 31:11-9.

34. Donnelly CA, Bartley LM, Ghani AC, Le Fevre AM, Kwong GP, Cowling BJ, et al. Gender difference in HIV-1 RNA viral loads. HIV Med 2005; 6:170-8.

35. Ministério da Saúde. Recomendações para terapia anti-retroviral em adultos e adolescentes infectados pelo HIV, 2004. http://www.aids.gov.br/data (acessado em 04/Dez/2005).

36. Hader SL, Smith DK, Moore JS, Holmberg SD. HIV infection in women in the United States-status at the millennium. JAMA 2001; 285:1186-92.

37. Gebo KA, Fleishman JA, Conviser R, Reilly ED, Todd-Korthuis P, Moore RD, et al. Racial and gender disparities in receipt of highly active antiretroviral therapy persist in a multi-state sample of HIV patients in 2001. J Acquir Immune Defic Syndr 2005; 38:96-103.

38. Strathdee AS, Palepu A, Cornelisse PGA, Yip B, O'Shaughnessy MV, Montaner JSG, et al. Barriers to use of free antiretroviral therapy in injection drug users. JAMA 1998; 280:547-9.

39. Joint United Nations Programme on HIV/AIDS Facts sheets on HIV/AIDS care and treatment. Geneva: Joint United Nations Programme on HIV/ AIDS; 2004.

40. Whetten K, Reif S, Lowe K, Eldred L. Gender differences in knowledge and perceptions of HIV resources among individuals living with HIV in the Southeast. South Med J 2004; 97:342-9.

Recebido em 28/Nov/2006

Versão final reapresentada em 04/Abr/2007 Aprovado em 16/Abr/2007 